\title{
Offering pregnant women different levels of genetic information from prenatal chromosome microarray: a prospective study
}

\author{
Jane L. Halliday ${ }^{1,2} \cdot$ Cecile Muller $^{1,3} \cdot{\text { Taryn } \text { Charles }^{1} \cdot \text { Fiona Norris }^{4} \cdot \text { Joanne Kennedy }}^{1} \cdot$ Sharon Lewis $^{1,2} \cdot$ \\ Bettina Meiser ${ }^{5}$ - Susan Donath ${ }^{1,2} \cdot$ Zornitza Stark $^{4} \cdot$ George McGillivray $^{1,6}$ - Melody Menezes ${ }^{1,7} \cdot$ Sian K. Smith $^{5}$. \\ Della Forster $^{8,9} \cdot$ Susan Walker ${ }^{10,11}$ - Mark Pertile ${ }^{4}$ David J. Amor ${ }^{1,2,12}$
}

Received: 20 August 2017 / Revised: 22 November 2017 / Accepted: 5 December 2017 / Published online: 6 February 2018

(c) European Society of Human Genetics 2018

\begin{abstract}
This study aimed to examine the choice pregnant women make about the amount of fetal genetic information they want from chromosome microarray. Women having invasive prenatal testing in the absence of fetal structural abnormality were recruited in Victoria, Australia. A decision aid for women described 'targeted' analysis as reporting only copy number variants implicated in a highly penetrant and well-described phenotype and 'extended' as additionally reporting variants of uncertain or unknown significance. Participant's choice and demographics were collected by survey before chorionic villus sampling or amniocentesis; psychological data were also collected then and again about 10 days after receiving results. High-resolution single-nucleotide polymorphism array analysis was performed, and a clinical review committee assessed variants for reporting before returning results to participants. Sixty-six participants $(59.5 \%)$ chose extended analysis and 45 $(40.5 \%)$ targeted. Choosing extended information was associated with (1) indication for prenatal diagnosis: maternal age alone (adjusted odds ratio (adjOR) 9.6, 95\% confidence interval (CI): 1.4-66.0, $p=0.02$ ), or 'other' indication (adjOR 7.1, 95\% CI: 1.5-33.1, $p=0.01)$ ); (2) >12 months to conceive (adjOR 4.1, 95\% CI: 1.0-17.7, $p=0.05$ ); and (3) Asian background (adjOR 4.67, 95\% CI: 1.0-21.0, $p=0.04$ ). No adverse psychological impact occurred in either group. We conclude that offering pregnant women different levels of fetal genetic analysis is warranted, alongside decision support.
\end{abstract}

\section{Introduction}

Chromosome microarray analysis (CMA) has been used in the prenatal setting since the mid-2000s, superseding traditional cytogenetic analysis [1]. Initially, prenatal CMA was used only in pregnancies with structural fetal abnormalities, but in 2012, a key publication demonstrated

Jane L. Halliday

janehalliday.h@mcri.edu.au

Murdoch Children's Research Institute, Melbourne, VIC, Australia

2 Department of Paediatrics, University of Melbourne, Melbourne, VIC, Australia

3 School of Psychology, University of Surrey, Guildford, Surrey, UK

4 Victorian Clinical Genetics Services, Murdoch Children's Research Institute, Melbourne, VIC, Australia

5 Prince of Wales Clinical School, UNSW Sydney, Sydney, NSW, Australia the superior performance of CMA in pregnancies with and without ultrasound abnormality [2]. This large multicentre study demonstrated that CMA detected an additional $6 \%$ of fetuses with chromosome abnormalities in the presence of a structural fetal abnormality and an extra $1.7 \%$ in the 'other' risk groups, largely through identification of submicroscopic copy number variants (CNVs) that affect

6 Royal Women's Hospital, Melbourne, VIC, Australia

7 Monash Ultrasound for Women, Melbourne, VIC, Australia

8 Judith Lumley Centre, La Trobe University, Melbourne VIC Australia

9 Midwifery and Maternity Services Research Unit, Royal Women's Hospital, Melbourne, VIC, Australia

10 Department of Obstetrics and Gynaecology, University of Melbourne, Melbourne, VIC Australia

11 Mercy Perinatal, Mercy Hospital for Women, Melbourne VIC Australia

12 The Royal Children's Hospital, Melbourne, VIC, Australia 
function, that is, those that encompass a region implicated in a well-described abnormal phenotype [2]. A recent systematic review pooled data on more than 10,500 fetuses without structural abnormality and gave a frequency of CNVs that affect function of $0.84 \%$ (95\% confidence interval: $0.55,1.30$ ) [3].

Not all CNVs detected are clinically helpful however and variants of uncertain or unknown significance (VOUS) create substantial counselling and ethical challenges in a prenatal setting, where there is no fetal phenotype to guide the interpretation of results and where they may be used to make a judgement about the potential for abnormal outcome and possible pregnancy termination [4-6]. Initially, this led to controversy about whether or not to extend CMA testing beyond pregnancies where a fetal abnormality had been detected on ultrasound [7]. Guidelines were slow to appear and still, by 2016, those of the American College of Obstetrics and Gynecology/Society of Maternal and Fetal Medicine were irresolute, saying that either conventional karyotyping or CMA can be performed where the fetus does not have a structural abnormality, regardless of maternal age [8]. Belgian consensus guidelines recommend CMA for all pregnancies [9], while UK guidelines support use of CMA in pregnancy when there is an ultrasound abnormality or nuchal translucency $\geq 3.5 \mathrm{~mm}$, but are silent about CMA use in other contexts [10]. Similarly, in Australia, CMA use is recommended as the first-tier chromosome test for pregnancies with fetal structural abnormalities with no mention of other indication groups [11].

With such open-ended recommendations for use of prenatal CMA, it is likely that some clinicians recommend it as a first-line test whenever fetal chromosomal analysis is planned, while others reserve CMA for cases in which there are fetal structural abnormalities, due to concern about VOUS. The Belgian guidelines specify a clear reporting policy that excludes them, but provides the option of using an ad hoc online national committee to consider ambiguous cases [9]. The UK guidelines recommend that VOUS unable to be linked to a potential phenotype should not be reported; [10] the Australian guidelines highlight the importance of genetic counselling for disclosing abnormal and VOUS results [11]. Largely absent from this discussion are the voices of those who will ultimately have to make reproductive choices based on results. To our knowledge, no study has yet asked parents directly about their preferences regarding VOUS.

As the use of CMA for prenatal diagnosis increases, there is a critical need to better understand how the information provided by high-resolution analysis will be interpreted, communicated to and understood by expectant couples. Our novel study offered women having prenatal diagnosis a choice with respect to the amount and type of fetal genetic information they wanted to receive. Two options were provided: 'extended' information including all CMA results (CNVs known to affect function, VOUS and benign) or 'targeted' information including only $\mathrm{CNVs}$ known to affect function or benign results. The aim was to examine how women responded to this choice in a real-time clinical setting, that is, to determine the actual uptake rate of either 'extended' or 'targeted' information. We also aimed to determine the psychosocial impact of the decision-making process, with a particular focus on measuring anxiety, decisional conflict and decisional regret.

\section{Materials and methods}

\section{Decision Aid}

A team of expert researchers and a graphic designer produced the original version of a decision aid after reviewing the relevant literature and consulting medical practitioners. The decision aid was then pilot-tested during five focus groups, consisting of 24 participants (17 women, 7 men, M age $=30.55$ years, $\mathrm{SD}=7.67$ years). Participants were mostly white, educated professionals and living near or in metropolitan Melbourne . For ethical reasons, none of them were expecting a child at the time of the study. During the focus groups, semi-structured discussions were guided by the use of a study-specific survey made up of closed and open-ended questions. The following themes were explored: overall layout and presentation, vocabulary and overall tone, knowledge and understanding. Data were analysed quantitatively and qualitatively and several changes were made to the wording and the format (e.g. A5 instead of A4). Overall, the final version was perceived as short, concise, visually aesthetic and easy to understand.

This document was designed to be a simple resource to support participants in deciding between the extended and targeted information options, and was available in hard copy and online (https://www.mcri.edu.au/sites/default/ files/media/documents/da_edit.pdf). The decision aid described the testing process (fluorescent in situ hybridisation (FISH) followed by CMA), the conditions detected by FISH (trisomies 13, 18, 21 and sex chromosome aneuploidies), and the types of results provided by CMA (no genetic variation, genetic variation known to impact on health and/or development and genetic variation with unknown or uncertain outcome). The decision aid also explained the differences between 'extended' and 'targeted' information options.

\section{Participants}

Participants were recruited from seven sites in Victoria, Australia, between September 2014 and October 2015; 
these included genetics clinics at three metropolitan public maternity hospitals, one rural genetic clinic and three private metropolitan obstetric ultrasound clinics. Eligible participants were English-speaking pregnant women who were scheduled to have chorionic villus sampling (CVS) or amniocentesis because of an increased risk prenatal screening result (maternal serum or non-invasive prenatal testing (NIPT)), advanced maternal age ( $\geq 37$ years) without any screening risk history, maternal request for reasons such as a twin or in vitro fertilisation pregnancy, or family history of a Mendelian disorder. Eligible participants also needed sufficient time (approximately 2-3 days) between receiving the study information and undergoing their procedure to complete the study requirements. Participants were excluded if they had a nuchal translucency $\geq 3.5 \mathrm{~mm}$ or abnormal fetal morphology on ultrasound.

Following standard antenatal care practice, women who had elected to undergo a CVS or amniocentesis were informed about the study by their private obstetrician or one of 13 tertiary qualified genetic counsellors at the antenatal clinics. (Fig. 1) Those who were interested in participating completed a 'consent to contact' form that was sent to the study genetic counsellor, who then rang the women to answer any questions, and to discuss the study requirements. Those then willing to participate completed a consent form (hard copy or online), were provided with the decision aid and were given until the day of the procedure to choose the type of fetal information they wished to receive ('extended' or 'targeted') and to complete Survey 1. Following the planned prenatal diagnosis procedure, the fetal sample was tagged as belonging to a study participant and sent to the Victorian Clinical Genetics Services (VCGS) for analysis.

\section{Laboratory testing}

The VCGS cytogenetic laboratory first performed a FISH test to identify common aneuploidy (trisomies 13, 18, 21 and sex chromosome aneuploidies). All samples were then tested using a single-nucleotide polymorphism (SNP) microarray (Affymetrix 750K or Illumina HumanCytoSNP$12 \mathrm{v} 2.1$ ). These platforms were routinely used for prenatal testing in the VCGS laboratory at the time the study was conducted [12]. The microarray data were then reported in one of two ways, according to participant choice (see Table 1).

\section{Targeted analysis}

This report included only abnormalities known to affect function with $100 \%$ penetrance, based on literature reports

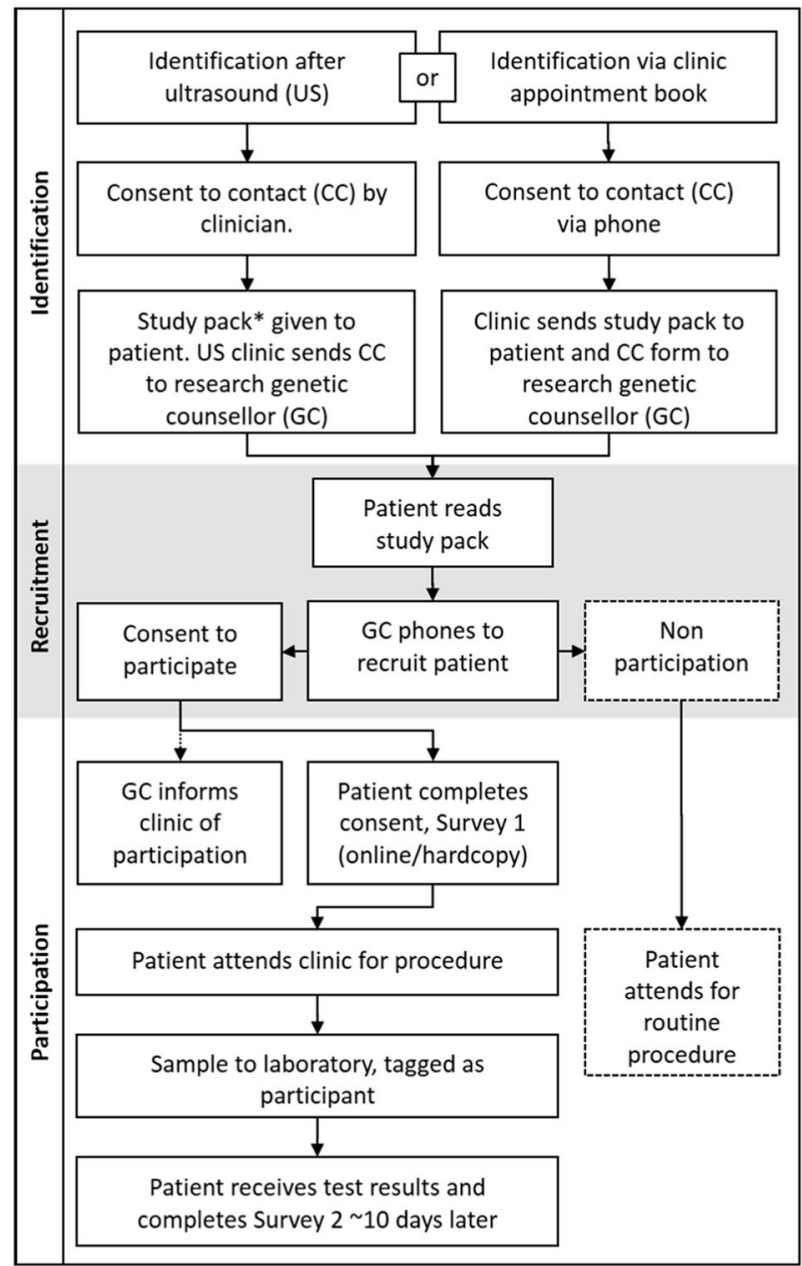

Fig. 1 Flowchart showing recruitment protocol and data collection points.

and gene content. Neuro-susceptibility loci, that is, those with $<100 \%$ penetrance, such as CNVs at 16p11.2, 15q13.3, were not reported back (see Table 1). Where required, decisions about classification of individual CNVs were made by a committee comprising VCGS clinical geneticists and laboratory scientists experienced in this area.

\section{Extended analysis}

This report included all CNVs known to affect function with $100 \%$ penetrance, as well as those with incomplete penetrance and VOUS.

Test results were returned to the participant by the referring doctor from the original recruitment site. In keeping with ethical requirements, the research team was only told whether the results were for CNVs that were known to affect function, VOUS or benign. 


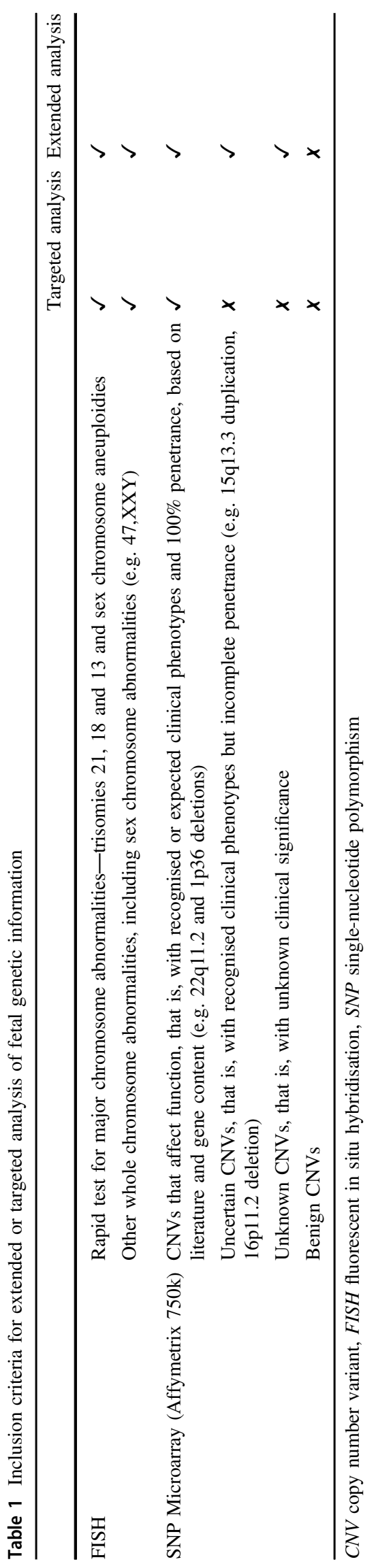

In both groups, incidental findings would be reported back according to VCGS policy which is to report those with health implications for the child or family, following discussion with the referring doctor.

\section{Surveys}

We designed two self-administered surveys comprising validated scales. Survey 1 , completed by women before having the procedure, collected data on demographics and reproductive history (Table 2), and measured decisional conflict [13], trait anxiety [14], state anxiety [15], attitudes towards uncertainty [16, 17], optimism [18] and perceived likelihood of carrying a child with a genetic abnormality [19]. Survey 1 also asked about participants' choice of 'targeted' or 'extended' fetal information. Survey 2 , sent to women approximately 10 days after they received the microarray result, measured resilience/ability to 'bounce back' [20], state anxiety [15] and decisional regret [21].

The indication for prenatal diagnosis was obtained from the VCGS laboratory and categorised as: (i) highrisk screening result for Down syndrome ( $<1$ in 150); (ii) increased risk screening result for Down syndrome (between 1 in 150 and 1 in 300); (iii) advanced maternal age $\geq 37$ years (with no screening result) or (iv) 'other' indication (e.g. maternal anxiety, prenatal diagnosis for Mendelian conditions).

\section{Data analysis}

Survey data were analysed using Stata version 14 (StataCorp LLC, TX, USA). Comparisons between the two outcome groups representing choice of analysis were undertaken using $\chi^{2}$ tests for categorical variables, independent $t$ tests (for normally distributed continuous predictor variables) and quantile regression (for nonnormally distributed continuous predictor variables). Tests for normality were done using the Shapiro-Wilk $W$ test.

Multivariable analyses to determine the independent predictors of choice were undertaken using logistic regression. Variables with $p$ values $\leq 0.2$ in the univariable analysis were included in the adjusted model to account for their possible confounding effect. Results are reported as odds ratios (ORs) and adjusted OR with $95 \%$ CIs and $p$ values.

Ethics approval was received from five committees, covering all recruitment sites (Epworth Health Care HREC (Project 635-14), The Royal Children's Hospital HREC (Project 34048), Mercy Health HREC (Project R14/10), The Women's Hospital HREC (Project 14/07) and Western Health HREC (Project 14/07)). 
Table 2 Characteristics of the study population by choice of fetal genetic analysis (targeted or extended), including unadjusted and adjusted odds ratios and $95 \%$ confidence intervals

\begin{tabular}{|c|c|c|c|c|c|}
\hline Characteristic & $\begin{array}{l}\text { Targeted } n=45 \\
(40.5 \%)\end{array}$ & $\begin{array}{l}\text { Extended } n=66 \\
(59.5 \%)\end{array}$ & $\chi^{2} p$ value & $\begin{array}{l}\text { Odds ratio }(95 \% \mathrm{CI}) \\
p \text { value (Ref.: targeted) }\end{array}$ & $\begin{array}{l}\text { Adjusted } \mathrm{OR}(95 \% \mathrm{CI}) \\
p \text { value }\end{array}$ \\
\hline Indication for prenatal diagnosis & & & $0.02^{\mathrm{a}}$ & & \\
\hline $\begin{array}{l}\text { Increased screening risk for } \\
\mathrm{T} 21: 1 / 150-1 / 300\end{array}$ & $17(56.7 \%)$ & $13(43.3 \%)$ & & Ref. & \\
\hline $\begin{array}{l}\text { High screening risk for } \mathrm{T} 21 \text { : } \\
>1 / 150\end{array}$ & $21(44.7 \%)$ & $26(55.3 \%)$ & & $1.6(0.6-4.1) p=0.31$ & $2.4(0.7-8.0) p=0.16$ \\
\hline $\begin{array}{l}\text { Advanced maternal age ( } \geq 37 \\
\text { years) }\end{array}$ & $2(11.8 \%)$ & $15(88.2 \%)$ & & $9.8(1.9-50.7) p<0.01$ & $9.6(1.4-66.0) p=0.02$ \\
\hline Other & $5(29.4 \%)$ & $12(70.6 \%)$ & & $3.1(0.9-11.2) p=0.08$ & $7.1(1.5-33.1) p=0.01$ \\
\hline Maternal age at recruitment & & & 0.92 & & \\
\hline$<30$ years & $6(42.9 \%)$ & $8(57.1 \%)$ & & Ref. & \\
\hline $30-34$ years & $10(43.5 \%)$ & $13(56.5 \%)$ & & $1.0(0.3-3.7) p=0.97$ & \\
\hline $35+$ years & $29(39.2 \%)$ & $45(60.8 \%)$ & & $1.2(0.4-3.7) p=0.80$ & \\
\hline Time to conceive & & & $<0.01^{\mathrm{a}}$ & & \\
\hline$<3$ months & $20(62.5 \%)$ & $12(37.5 \%)$ & & Ref. & Ref. \\
\hline 3-12 months & $13(48.1)$ & $14(51.9 \%)$ & & $1.8(0.6-5.1) p=0.27$ & $1.3(0.4-4.2) p=0.67$ \\
\hline $12+$ months & $4(21.0 \%)$ & $15(78.9 \%)$ & & $6.3(1.7-23.3) p<0.01$ & $4.1(1.0-17.7) p=0.05$ \\
\hline Were not trying (unplanned) & $7(26.9 \%)$ & $19(73.1 \%)$ & & $4.5(1.5-14.0) p<0.01$ & $3.4(0.9-12.7) p=0.07$ \\
\hline Missing & 1 & 6 & & & \\
\hline Fertility treatment & & & $<0.01$ & & \\
\hline No & $44(45.4 \%)$ & $53(54.6 \%)$ & & Ref. & \\
\hline Yes & $1(7.7 \%)$ & $12(92.3 \%)$ & & $10.0(1.3-80.0) p=0.03$ & \\
\hline Pregnancy number & & & 0.39 & & \\
\hline 1 & $5(35.7 \%)$ & $9(64.3 \%)$ & & Ref. & \\
\hline 2 & $18(50.0 \%)$ & $18(50.0 \%)$ & & $0.6(0.2-2.0) p=0.37$ & \\
\hline 3 & $7(30.4 \%)$ & $16(69.6 \%)$ & & $1.3(0.3-5.2) p=0.74$ & \\
\hline 4 & $8(53.3 \%)$ & $7(46.7 \%)$ & & $0.5(0.1-2.2) p=0.34$ & \\
\hline $5+$ & $7(31.8 \%)$ & $15(68.2 \%)$ & & $1.2(0.3-4.9) p=0.81$ & \\
\hline Born in Australia & & & 0.42 & & \\
\hline No & $12(34.3 \%)$ & $23(65.7 \%)$ & & Ref. & \\
\hline Yes & $31(42.5 \%)$ & $42(57.5 \%)$ & & $0.7(0.3-1.6) p=0.42$ & \\
\hline First language & & & 0.54 & & \\
\hline English & $36(41.9 \%)$ & $50(58.1 \%)$ & & Ref. & \\
\hline Other & $8(34.8 \%)$ & $15(65.2 \%)$ & & $1.4(0.5-3.5) p=0.54$ & \\
\hline Ethnicity & & & $0.21^{\mathrm{a}}$ & & \\
\hline Caucasian & $32(46.4 \%)$ & $37(53.6 \%)$ & & Ref. & Ref. \\
\hline Asian & $4(23.5 \%)$ & $13(76.5 \%)$ & & $2.8(0.8-9.5) p=0.10$ & $4.7(1.0-21.0) p=0.04$ \\
\hline Other & $9(37.5 \%)$ & $15(62.5 \%)$ & & $1.4(0.6-3.7) p=0.45$ & $2.3(0.7-7.2) p=0.15$ \\
\hline Religion & & & 0.67 & & \\
\hline Catholic & $12(50.0 \%)$ & $12(50.0 \%)$ & & Ref. & \\
\hline Other Christian & $7(33.3 \%)$ & $14(66.7 \%)$ & & $2.0(0.6-6.7) p=0.26$ & \\
\hline Other & $6(35.3 \%)$ & $11(64.7 \%)$ & & $1.8(0.5-6.6) p=0.35$ & \\
\hline No religion & $20(41.7 \%)$ & $28(58.3 \%)$ & & $1.4(0.5-3.8) p=0.50$ & \\
\hline Completed level of education & & & 0.58 & & \\
\hline Diploma/apprenticeship & $15(39.5 \%)$ & $23(60.5 \%)$ & & Ref. & \\
\hline Secondary school & $6(54.5 \%)$ & $5(45.4 \%)$ & & $0.5(0.1-2.1) p=0.38$ & \\
\hline Undergraduate degree & $7(30.4 \%)$ & $16(69.6 \%)$ & & $1.5(0.5-4.5) p=0.48$ & \\
\hline
\end{tabular}


Table 2 (continued)

\begin{tabular}{|c|c|c|c|c|c|}
\hline Characteristic & $\begin{array}{l}\text { Targeted } n=45 \\
(40.5 \%)\end{array}$ & $\begin{array}{l}\text { Extended } n=66 \\
(59.5 \%)\end{array}$ & $\chi^{2} p$ value & $\begin{array}{l}\text { Odds ratio }(95 \% \mathrm{CI}) \\
p \text { value (Ref.: targeted) }\end{array}$ & $\begin{array}{l}\text { Adjusted OR }(95 \% \mathrm{CI}) \\
p \text { value }\end{array}$ \\
\hline Postgraduate degree & $15(42.9 \%)$ & $20(57.1 \%)$ & & $0.9(0.3-2.2) p=0.77$ & \\
\hline Occupational status & & & 0.80 & & \\
\hline Employed full- time & $15(40.5 \%)$ & $22(59.5 \%)$ & & Ref. & \\
\hline Employed part-time or casual & $19(46.3 \%)$ & $22(53.7 \%)$ & & $0.8(0.3-1.9) p=0.61$ & \\
\hline Home duties & $8(34.8 \%)$ & $15(65.2 \%)$ & & $1.3(0.4-3.8) p=0.66$ & \\
\hline Student/other & $2(33.3 \%)$ & $4(66.7 \%)$ & & $1.4(0.2-8.4) p=0.74$ & \\
\hline Financial situation & & & $0.19^{\mathrm{a}}$ & & \\
\hline Living comfortably & $19(52.8 \%)$ & $17(47.2 \%)$ & & Ref. & Ref. \\
\hline Doing alright & $19(38.0 \%)$ & $31(62.0 \%)$ & & $1.8(0.8-4.3) p=0.17$ & $1.7(0.6-5.0) p=0.35$ \\
\hline $\begin{array}{l}\text { Just getting by/finding it quite } \\
\text { difficult }\end{array}$ & $7(30.4 \%)$ & $16(69.6 \%)$ & & $2.6(0.9-7.7) p=0.10$ & $3.1(0.8-11.8) p=0.10$ \\
\hline
\end{tabular}

${ }^{\text {a }}$ Included in multivariable analysis as covariates

\section{Results}

Of the 111 pregnant women recruited, 66 (59.5\%) opted for extended analysis and 45 (40.5\%) chose targeted. As shown in Table 2, only three variables differed significantly in expected frequency among these two outcome groups $(p<$ 0.05 ): indication for having prenatal diagnosis, time to conceive and use of fertility treatment. Women who had prenatal diagnosis for advanced maternal age only ( $\geq 37$ years) were over-represented among those who chose extended information $(88.2 \%)$, as were women who had prenatal diagnosis for 'other' reasons $(70.6 \%)$. Of note, amongst this 'other' indication category, the proportion of women having testing for maternal anxiety or for Mendelian conditions was similar in each outcome group. Amongst those who conceived in $<3$ months, more women chose targeted information (62.5\%). Conversely, those who took longer than 12 months to conceive and those who had not been trying to conceive (i.e. had an unplanned pregnancy) chose extended information more frequently (78.9 and $73.1 \%$, respectively). Almost all women who had had fertility treatment $(92.3 \%)$ chose extended information.

\section{Predictors of choice}

Table 2 also shows the results of univariable and multivariable logistic regression analysis. Five variables had $p$ values $\leq 0.2$ in univariable analysis, that is, indication for prenatal diagnosis, time to conceive, fertility treatment, ethnicity and financial situation. These variables were entered into a multiple regression as covariates, except for fertility treatment, which was not entered as there was only one woman having fertility treatment in the targeted group.
Statistically significant independent predictors of choosing extended information included advanced maternal age (adjOR 9.6, 95\% CI: 1.4-66.0, $p=0.02$ ), and 'other' indication for the test (adjOR 7.1, 95\% CI: 1.5-33.1, $p=0.01$ ). Women who took more than 12 months to conceive were more likely to choose extended information (adjOR 4.1, 95\% CI: $1.0-17.7, p=0.05)$ compared to women who conceived in $<3$ months, and there was an attenuated positive association between having an unplanned pregnancy and choosing extended information (adjOR 3.4, 95\% CI: $0.9-12.7, p=0.07$ ). Being of Asian background was associated with an almost five times greater likelihood of choosing extended information compared to Caucasian women (adjOR 4.7, 95\% CI: 1.0-21.0, $p=0.04)$. Financial situation ('just getting by') was not significantly associated with choice, but the adjusted odds ratio showed a greater likelihood of choosing extended in this group compared with those 'living comfortably' (adjOR 3.1, 95\% CI: $0.8-11.8, p=0.10$ ).

\section{Psychological measures over time}

\section{Pre-diagnostic procedure, that is, before the CVS or amniocentesis}

Table 3 shows the means and standard deviations of the psychological scales separately for the targeted and extended analysis groups. Those who chose extended information were generally more anxious than those who chose targeted $(p=0.05)$. The average level of state anxiety at the time was slightly higher than population norms in both groups; a cutoff of 40 is defined as clinically important [17]. There were no between group differences for the other measures. 
Table 3 Psychological measures: pre-diagnostic procedure and post-test CMA results

\begin{tabular}{|c|c|c|c|c|}
\hline Pre-diagnostic procedure results & $\begin{array}{l}\text { Targeted } \\
(n=45) \text { Mean }(\mathrm{SD})\end{array}$ & $\begin{array}{l}\text { Extended }(n= \\
66) \text { Mean (SD) }\end{array}$ & Mean diff $(95 \% \mathrm{CI})$ & $\begin{array}{l}p \text { value } \\
(t \text { test })\end{array}$ \\
\hline Decisional conflict (range 0-60) & $21.8(13.0)$ & $19.4(12.1)$ & $-2.4(-7.1$ to 2.4$)$ & 0.33 \\
\hline STAI-trait anxiety (range $20-80$ ) & $36.2(6.8)$ & $39.5(9.3)$ & $3.3(0.05$ to 6.5$)$ & 0.05 \\
\hline STAI-state anxiety (range 20-80) & $43.9(14.7)$ & $44.8(14.6)$ & $0.9(-4.7$ to 6.5$)$ & 0.76 \\
\hline Intolerance of uncertainty (range 10-50) & $29.5(6.5)$ & $31.0(8.0)$ & $1.5(-1.4$ to 4.3$)$ & 0.31 \\
\hline Life orientation test (range 5-25) & $16.0(3.2)$ & $15.1(3.9)$ & $-0.9(-2.3$ to 0.5$)$ & 0.18 \\
\hline $\begin{array}{l}\text { Perceived likelihood of carrying a child with a } \\
\text { genetic abnormality (range }-0.3-3 \text { ) }\end{array}$ & $-0.27(1.3)$ & $-0.35(1.3)$ & $-0.1(-0.6$ to 0.4$)$ & 0.75 \\
\hline Post-test results & $\begin{array}{l}\text { Targeted } \\
(n=35) \text { Mean }(\mathrm{SD})\end{array}$ & $\begin{array}{l}\text { Extended } \\
(n=52) \text { Mean }(\mathrm{SD})\end{array}$ & Mean diff $(95 \% \mathrm{CI})$ & \\
\hline \multirow[t]{2}{*}{ Brief Resilience Scale (range 2-5) } & $3.6(0.5)$ & $3.4(0.67)$ & $-0.2(-0.5$ to 0.04$)$ & 0.11 \\
\hline & Median & Median & $\begin{array}{l}\text { Difference of medians } \\
(95 \% \mathrm{CI})\end{array}$ & $p$ value \\
\hline STAI-state anxiety (range 20-80) & 30 & 33.3 & $-3.3(-10.8$ to 4.1$)$ & 0.38 \\
\hline Decisional regret (range $0-50$ ) & 15 & 5 & $10(1.2$ to 18.8$)$ & 0.03 \\
\hline
\end{tabular}

CMA chromosome microarray, STAI State-Trait Anxiety Inventory

\section{Post-microarray test results}

Twenty-eight women (25\%) did not complete Survey 2 (15 extended and 13 targeted), four of whom had abnormal microarray results and were not sent a reminder. Of these non-responders, $50 \%$ had a state anxiety measure below 40 in Survey 1 compared with $33 \%$ of those who went on to complete Survey 2. There was a slight over-representation of non-Caucasian women $(n=10)$ amongst non-responders to Survey 2, but no other differences were seen.

State anxiety and decisional regret scores (DRS) were not normally distributed: there was a strong skew towards lower scores in both groups. In both extended and targeted groups, state anxiety scores had declined substantially to well within population norm values, although they remained slightly higher in the extended group. Conversely, the targeted group demonstrated more decisional regret than the extended group ( $p=$ 0.03 ), but again the median score was within the normal range.

On examination of Survey 2 records for women receiving an abnormal $(n=6)$ or VOUS $(n=4)$ result, the DRS median was higher for the VOUS (35) than the abnormals (12.5) or normals (5). If all Survey 2 records for women receiving an abnormal or VOUS result were excluded from the analysis, there were no changes in the anxiety results, the DRS medians remained the same, but the $p$ value for the DRS changed from 0.03 to 0.02 with a tighter CI (1.4-18.5).

\section{Discussion}

We have shown that women who are given a choice about how much fetal genetic information to receive from a CMA following CVS or amniocentesis are demonstrating a clear preference for one of two quite different options. A slight majority of women in our study $(60 \%)$ chose extended information, but a substantial percentage $(40 \%)$ chose targeted. Our data indicate that when women carrying a fetus without a detected ultrasound abnormality are offered a choice, provided with a decision aid, and given time to consider options, they are able to participate in such decision-making without any adverse short-term psychological effects. This finding provides evidence for the need to ensure that having a choice between extended and targeted testing is available in pregnancy and that laboratories and clinical services are designed and resourced to facilitate this. Reporting on all results has been the standard practice to date, leaving test result delivery to the discretion of referring clinicians, potentially irrespective of parents' preferences.

Clearly, the most significant drawback to the use of CMA for prenatal diagnosis has been the potential detection of VOUS. Given the harm such information can have on pregnant women [5], there is an argument that it should be withheld [4, 22].

There is very little research about the amount of fetal information pregnant women might want from CMA. In the clinical setting, the issue has been looked at by just one Dutch study, which offered 59 women who were having prenatal diagnosis a choice between a lower resolution $5 \mathrm{Mb}$ array and a higher resolution $0.5 \mathrm{Mb}$ array (detecting more abnormalities), and between whether they wished to receive information about susceptibility loci or not [23]. Susceptibility loci are defined as known to affect function, but with expression and severity that are difficult to predict. Amongst these women, 94\% chose the high-resolution array 
and $84 \%$ of these women wanted to know about susceptibility loci. In our study, the percentage who chose the 'targeted' option (40\%) is much higher than the percentage who chose the lower resolution array $(6 \%)$ in the Dutch study. However, it is notable that our targeted analysis would have detected some CNVs that are known to affect function, but which would have been missed by the Dutch $5 \mathrm{Mb}$ array; this may have given our participants more confidence to choose this option.

Research into preferences women have for NIPT versus traditional prenatal diagnosis following a high-risk screening result also supports the premise that women will have different priorities and will make different choices, given the chance to do so; even if in this case, their choice is most likely related to safety of testing rather than information depth or turnaround time for a result. One study reported that $60 \%$ of women with a high-risk maternal serum screen in the first-trimester wanted NIPT for follow-up aneuploidy screening compared to $38 \%$ who wanted invasive prenatal diagnosis [24]. Similar figures were seen in another study, with $74 \%$ wanting NIPT and $18 \%$ prenatal diagnosis [25]. The latter paper concludes with a statement that the option to make an informed decision about having NIPT versus prenatal diagnosis is required outside of a research setting. We would expand that recommendation to include choice of not just the type of test but also amount of information from the CMA if prenatal diagnosis is chosen. Our results are relevant to other current and future prenatal sequencing technologies that will also produce VOUS, for example, advances in NIPT to include more widespread sequencing beyond the major chromosomal aneuploidies and common microdeletions [26].

Outside the pregnancy setting and concerning sequencing rather than microarray technology, a recent study of 790 children and adults with suspected monogenic disorders has examined the choices people make about receipt of primary and secondary genomic research results [27]. Secondary findings are not specifically related to the medical condition being investigated in the patient, but relate to genes associated with 59 medically actionable conditions recommended for analysis and return of results. Researchers found that at least $20 \%$ of all participants did not want all results possible, again highlighting the importance of providing choice [27]. Provision of choice is included in a recent revision of the American College of Medical Genetics policy on reporting of variants from clinical genome-scale sequencing [28]. The College now allows for an option for patients to decline secondary finding analysis, following appropriate counselling [28].

In our study, multivariable analysis demonstrated several significant independent predictors of choice of either targeted or extended analysis. First, women who were of advanced maternal age ( $\geq 37$ years) and sought prenatal diagnosis without having had a screening test chose extended information most frequently. This desire for more in-depth information is consistent with the possibility that, by having prenatal diagnosis as a first-line test, they already had a high level of concern about their unborn child, wanting as much information as quickly as possible. Second, women who reported having taken more than 12 months to conceive were also more likely to choose extended testing. One possible explanation is that these women sought information from the most 'complete' test, which could provide greater reassurance about the health of a much awaited child. Likewise, when a pregnancy was unplanned, the frequent choice of extended analysis may reflect parental anxiety about inadvertent exposures, such as alcohol use before pregnancy awareness.

Finally, being of Asian ethnicity in our population had an almost five-fold increased likelihood of choosing extended information. This outcome is consistent with research findings demonstrating lower personal utility of a fetus diagnosed with Down syndrome in a Chinese population [29]. Similarly, a more recent study examining hypothetical preferences in relation to prenatal testing for microdeletions and duplications found that being of Asian ethnicity was significantly associated with choosing an invasive test as opposed to NIPT or no test at all [30]. This further indicates the interest in more in-depth testing amongst this population group.

There was weak evidence that those 'just getting by' financially, or 'finding it quite difficult', were more likely to want extended information than those 'living comfortably', perhaps to avoid medical expenses that might arise in a child with health problems. All of these reasons are speculative and warrant further follow-up in a qualitative study as no empirical data are yet available on such decision-making.

\section{Study strengths and limitations}

A strength of this study was that it was undertaken in real time, and was not dependent on hypothetical scenarios. In addition, the women recruited were likely to be representative of the general population having prenatal diagnosis in metropolitan regions, as they were from both private and public antenatal care services. There were, however, less than five women recruited from rural regions. An aspect that could be perceived as a limitation was the small sample size. Unexpected recruitment difficulties were a direct result of a reduction in eligible women because of the rapid uptake of NIPT in Victoria during 2014-2015, and therefore illustrative of a concomitant decrease in number of women having prenatal diagnosis [31]. Fortunately, although the final sample size was not as large as planned, we have been able to demonstrate significant associations because of the 60:40 distribution of women between the two choices. Another potential limitation in our assessment of 
the psychological impact of making a choice was that $25 \%$ of women did not complete the second survey. On examination of their Survey 1 levels of state anxiety, there was no excessive attrition by one group over another and those lost to follow-up were less anxious on average than those who continued to participate, thus potentially biasing our Survey 2 findings away from the null hypothesis. However, as we did not find strong associations between the two groups in post-test measures, it is unlikely that there has been an effect of participation bias. Further longitudinal studies would be needed to examine whether group differences in decisional regret persist over time.

\section{Clinical implications}

The time taken by the research genetic counsellor with each participant was recorded and all except five telephone calls were conducted in $<20 \mathrm{~min}$, with most being about $10 \mathrm{~min}$. Given that 6 of the 7 clinics in this study had genetic counsellors seeing the participant prior to the procedure, we suggest that $10 \mathrm{~min}$ of extra time would need to be added to provide and explain the purpose of the decision aid (DA). We recognise that a DA alone cannot guarantee informed decision-making, nor replace the rich interaction that may take place between genetic counsellors and expectant parents. However, a DA adapted from the one used in this study could minimise the extra genetic counselling time required if such choices were offered to expectant parents, and help pave the way forward to increased shared decisions. Our results show that participants' preferences do vary, yet as far as we are aware, no guidelines currently recommend that these preferences be offered and formally assessed in clinical settings. Making such decisions available to expectant couples will present practical and clinical challenges, but failing to do so is also problematic.

In a medical era that promotes patient-centred decisionmaking, offering individualised choice about the scope and depth of prenatal genetic analysis seems more important than ever, especially when there is no fetal abnormality on ultrasound, and therefore no phenotype to help in decisionmaking [32]. Whilst our results need to be verified by longterm follow-up studies, they indicate the absence of high levels of anxiety or regret following receipt of chosen test results. Therefore, the findings support the premise that people have a right not to know, not to be conflicted, anxious and potentially confused by having uncertain or unknown results returned to them [33].

Providing choice about the complex testing possibilities, and eliciting parental preference for the prenatal genetic analysis desired, in the limited time often available prior to testing, is a huge challenge [34]. Use of a DA as in this study (which was reported in Survey 1 as useful by $96.4 \%$ of participants), or an interactive decision-support tool as used in randomised controlled trials to inform pregnant women of their prenatal testing options, may assist $[35,36]$. Pre-test genetic counselling will also facilitate greater understanding of all the testrelated information, enabling a personalised approach to decision-making and is highly recommended [37].

We have shown that laboratories can offer a two-tier CMA reporting system successfully for a research study, but questions remain as to the sustainability of this process and the medico-legal ramifications if possibly abnormal results are withheld, even at the patient's request [9].

\section{Conclusion}

Given a choice, women do make different decisions about the amount of fetal genetic information they want from CMA testing, and can negotiate this choice without evident short-term adverse psychological sequelae. Our results support a recommendation for offering different levels of genetic analysis to pregnant women who are undergoing screening and diagnostic testing. In the current context, lacking clear guidelines about the return of VOUS and leaving clinicians having to decide what results to share with patients, it seems imperative to involve expectant couples in their own reproductive decision-making which will impact on the rest of their lives.

Acknowledgements We would like to acknowledge all the research genetic counsellors who recruited participants and contributed to the design and implementation of the research, particularly Susan Fawcett. All practice managers and medical staff at sites involved are also thanked. VCGS laboratory personnel involved in review and reporting of results included David Francis and the laboratory head at the time, Howard Slater, who facilitated the two-tier reporting approach.

Funding Jane Halliday and Bettina Meiser were supported through National Health and Medical Research Council (NHMRC) Senior Fellowships, Level B, numbers 1021252 and 1078523 respectively. The research project was also funded by NHMRC (grant number 1059993). This work was made possible through the Victorian State Government Operational Infrastructure Support and Australian Government NHMRC IRIISS.

\section{Compliance with ethical standards}

Conflict of interest The authors declare that they have no conflict of interest

\section{References}

1. Le Caignec C, Boceno M, Saugier-Veber P, Jacquemont S, Joubert M, David A, et al. Detection of genomic imbalances by array based comparative genomic hybridisation in fetuses with multiple malformations. J Med Genet. 2005;42:121-8.

2. Wapner RJ, Martin CL, Levy B, Ballif BC, Eng CM, Zachary JM, et al. Chromosomal microarray versus karyotyping for prenatal diagnosis. N Engl J Med. 2012;367: 2175-84. 
3. Srebniak MI, Joosten M, Knapen M, Arends LR, Polak M, van Veen $\mathrm{S}$, et al. Frequency of submicroscopic chromosome aberrations in pregnancies without increased risk for structural chromosome aberrations: a systematic review of literature and meta-analysis. Ultrasound Obstet Gynecol. 2017. https://doi.org/10.1002/uog.17533

4. McGillivray G, Rosenfeld JA, McKinlay Gardner RJ, Gillam LH. Genetic counselling and ethical issues with chromosome microarray analysis in prenatal testing. Prenat Diagn. 2012;32:389-95.

5. Bernhardt BA, Soucier D, Hanson K, Savage M, Jackson LG, Wapner RJ. Women's experiences receiving abnormal prenatal chromosomal microarray testing results. Genet Med. 2012;15:139-45.

6. Stark Z, Gillam L, Walker SP, McGillivray G. Ethical controversies in prenatal microarray. Curr Opin Obstet Gynecol. 2013;25:133-7.

7. Crolla JA, Wapner R, Van Lith JMM. Controversies in prenatal diagnosis 3: should everyone undergoing invasive testing have a microarray? Prenat Diagn. 2014;34:18-22.

8. American College of Obstetrics and Gynecologists. Committee on Genetics Society for Maternal-Fetal Medicine. Committee Opinion no 682: microarrays and next generation sequencing technology: the use of advanced genetic diagnostic tools in obstetrics and gynecology. Obstet Gynecol. 2016;128:e262-e268.

9. Vanakker O, Vilain C, Janssens K, Van der Aa N, Smits G, Bandelier $\mathrm{C}$, et al. Implementation of genomic arrays in prenatal diagnosis: The Belgian approach to meet the challenges. Eur $\mathbf{J}$ Med Genet. 2014;57:151-6.

10. Gardiner C, Wellesley D, Kilby M, Kerr B. Recommendations for the use of chromosome microarray in pregnancy. London: The Royal College of Pathologists, PUB 290615; 2015.

11. Royal Australian and New Zealand College of Obstetricians and Gynaecologists. Prenatal screening and diagnosis of chromosomal and genetic conditions in the fetus in pregnancy. C-Obs 59. Royal Australian and New Zealand College of Obstetricians and Gynaecologists; 2016.

12. Ganesamoorthy D, Bruno DL, McGillivray G, Norris F, White S. M., Adroub S, et al. Meeting the challenge of interpreting highresolution single nucleotide polymorphism array data in prenatal diagnosis: does increased diagnostic power outweigh the dilemma of rare variants? BJOG. 2013;120:594-606.

13. O'Connor AM. Validation of a decisional conflict scale. Med Decis Making. 1995;15:25-30.

14. Spielberger CD, Van der Aa N., Smits, G, Bandelier C, Manual for the State-Trait Anxiety Inventory (STAI). Palo Alto, CA: Consulting Psychologists Press; 1983.

15. Marteau TM, Bekker H. The development of a six-item short-form of the state scale of the Spielberger State-Trait Anxiety Inventory (STAI). Br J Clin Psychol. 1992;31:301-6.

16. Braithwaite D, Sutton S, Steggles N. Intention to participate in predictive genetic testing for hereditary cancer: the role of attitude toward uncertainty. Psychol Health. 2002;17:761-72.

17. Carleton RN, Norton MAPJ, Asmundson GJG. Fearing the unknown: a short version of the Intolerance of Uncertainty Scale. J Anxiety Disord. 2007;21:105-17.

18. Scheier MF, Carver CS, Bridges MW. Distinguishing optimism from neuroticism (and trait anxiety, self-mastery, and self-esteem): a reevaluation of the Life Orientation Test. J Pers Soc Psychol. 1994;67:1063-78.

19. Muller C, Cameron LD. Trait anxiety, information modality, and responses to communications about prenatal genetic testing. J Behav Med. 2014;37:988-99.

20. Smith BW, Dalen J, Wiggins K, Tooley E, Christopher P, Bernard J. The brief resilience scale: assessing the ability to bounce back. Int J Behav Med. 2008;15:194-200.
21. Brehaut JC, O'Connor AM, Wood TJ, Hack TF, Siminoff L, Gordon E, et al. Validation of a decision regret scale. Med Decis Making. 2003;23:281-92.

22. Shkedi-Rafid S, Fenwick A, Dheensa S, Wellesley D, Lucassen AM. What results to disclose, when, and who decides? Healthcare professionals' views on prenatal chromosomal microarray analysis. Prenat Diagn. 2016;36:252-9.

23. van der Steen SL, Diderich KE, Riedijk SR, Verhagen-Visser J, Govaerts LC, Joosten M, et al. Pregnant couples at increased risk for common aneuploidies choose maximal information from invasive genetic testing. Clin Genet. 2015;88: 25-31.

24. Gil M, Revello R, Poon L, Akolekar R, Nicolaides K. Clinical implementation of routine screening for fetal trisomies in the UK NHS: cell-free DNA test contingent on results from first-trimester combined test. Ultra Obstet Gynecol. 2016;47:45-52.

25. Chitty L, Wright D, Hill M, Verhoef T, Daley R, Lewis C, et al. Uptake, outcomes, and costs of implementing non-invasive prenatal testing for Down's syndrome into NHS maternity care: prospective cohort study in eight diverse maternity units. BMJ. 2016;354:i3426.

26. Wapner RJ, Babiarz JE, Levy B, Stosic M, Zimmermann B, Sigurjonsson $\mathrm{S}$, et al. Expanding the scope of noninvasive prenatal testing: detection of fetal microdeletion syndromes. Am J Obstet Gynecol. 2015;212:332.e1-339.

27. Fiallos K, Applegate C, Mathews DJ, Bollinger J, Bergner AL, James CA. Choices for return of primary and secondary genomic research results of 790 members of families with Mendelian disease. Eur J Hum Genet. 2017;25:530-7.

28. Kalia SS, Adelman K, Bale SJ, Chung WK, Eng C, Evans JP, et al. Recommendations for reporting of secondary findings in clinical exome and genome sequencing, 2016 update (ACMG SFv2.0): a policy statement of the American College of Medical Genetics and Genomics. Genet Med. 2017;19:249-55.

29. Chan YM, Leung TN, Leung TY, Fung TY, Chan LW, Lau TK, The utility assessment of Chinese pregnant women towards the birth of a baby with Down syndrome compared to a procedurerelated miscarriage. Prenat Diagn. 2006;26:819-24.

30. Calonico E, Blumenfeld YJ, Hudgins L, Taylor J. Patient preferences for prenatal testing of microdeletion and microduplication syndromes. Prenat Diagn. 2016;36:244-51.

31. Hui L, Hutchinson B, Poulton A, Halliday J, Population-based impact of noninvasive prenatal screening on screening and diagnostic testing for fetal aneuploidy. Genet Med. 2017;19:1338-45. doi:https://doi.org/10.1038/gim.2017.55.

32. Westerfield L, Darilek S, van den Veyver IB. Counselling challenges with variants of uncertain significance and incidental findings in prenatal genetic screening and diagnosis. J Clin Med. 2014;3:1018-32.

33. Scientific American Editors. Beware the destiny test. Sci Am Online. 2013;308:12.

34. Dolan SM. Personalized genomic medicine and prenatal genetic testing. JAMA. 2014;312:1203-5.

35. Kuppermann M, Pena S, Bishop JT, Nakagawa S, Gregorich SE, Sit A, et al. Effect of enhanced information, values clarification, and removal of financial barriers on use of prenatal genetic testing: a randomized clinical trial. JAMA. 2014;312:1210-7.

36. Beulen L, van den Berg M, Faas BH, Feenstra I, Hageman M, van Vugt JM, et al. The effect of a decision aid on informed decisionmaking in the era of non-invasive prenatal testing: a randomised controlled trial. Eur J Hum Genet. 2016;24:1409-16.

37. Walser SA, Kellom KS, Palmer SC, Bernhardt BA. Comparing genetic counselor's and patient's perceptions of needs in prenatal chromosomal microarray testing. Prenat Diagn. 2015;35:870-8. 